ANUARIO DE Estudios MEdiEVALES 44/1, enero-junio de 2014, pp. 179-213

ISSN 0066-5061

doi:10.3989/aem.2014.44.1.06

\title{
¿FAVORITAS DE LA CORONA? \\ LOS AMORES DEL REY Y LA PROMOCIÓN DE LA ORDEN DE SANTA CLARA EN CASTILLA (SS. XIII-XIV) ${ }^{1}$
}

\author{
FAVORITES OF THE CROWN? \\ THE LOVES OF THE KING AND THE PROMOTION OF \\ THE ORDER OF SAINT CLARE IN CASTILE \\ (13th-14th CENTURIES)
}

\author{
MARÍA DEL MAR GRAÑA Cid \\ Universidad Pontificia de Comillas (Madrid)
}

\begin{abstract}
Resumen: En la política de promoción de las monjas mendicantes que desarrollaron los reyes de Castilla se percibe una tipología de "fundaciones en relación" con mujeres. Alfonso X y Pedro I colaboraron con sus amantes, Mayor Guillén y María de Padilla, y el segundo también con sus hijas, Beatriz e Isabel, para dar origen a monasterios de la Orden de Santa Clara o de sus formas previas. Estas páginas analizan unos procesos de fundación que enlazan lo personal y lo familiar con lo político, visibilizan formas de interacción entre los sexos y desvelan algunas de las fisonomías adoptadas por las religiosas que constituyeron la institución clarisa, una orden religiosa exclusivamente femenina en la que tuvieron gran peso las mujeres como agentes históricos.
\end{abstract}

Palabras clave: reyes de Castilla; monjas mendicantes; Orden de Santa Clara; clarisas; favoritas; hijas bastardas; Alfonso X; Pedro I.

\begin{abstract}
The promotion of female mendicant houses by the kings of Castile offers a typology of "partnering foundations" associated with women. Alfonso X and Pedro I collaborated with their lovers, Mayor Guillén and María de Padilla, and the latter also with his daughters, Beatriz and Isabel, in order to create monasteries of the Order of Saint Clare or its previous forms. These pages analyse the foundational processes that connect the familiar with the political and the personal, offer visible forms of interaction between sexes and reveal some of the physiognomies adopted by the nuns that constituted an exclusively female religious order in which women acted as its main historical agents.
\end{abstract}

Keywords: kings of Castile; mendicant nuns; Order of Saint Clare; Poor Clares; royal mistresses; illegitimate daughters; Alfonso X; Pedro I.

\footnotetext{
1 Abreviaturas utilizadas: $\mathrm{AGP}=$ Archivo General de Palacio (Madrid); $\mathrm{AHN}=$ Archivo Histórico Nacional (Madrid); AMA = Archivo Municipal de Alcocer; ASCA = Archivo del monasterio de Santa Clara de Astudillo (Palencia); ASCT = Archivo del monasterio de Santa Clara de Tordesillas (Valladolid).
} 


\section{SUMARIO}

1. Procesos fundacionales y tipologías monásticas.-1.1. Santa María de San Miguel del Monte: Mayor Guillén de Guzmán y Alfonso X.- 1.2. Santa Clara de Astudillo: María de Padilla y Pedro I.- 1.3. Santa María de Tordesillas: las infantas Beatriz e Isabel y Pedro I.- 2. La fundación monástica como vía de empoderamiento femenino.- 3. La participación de los reyes y sus políticas.- 4. Un simbólico femenino al servicio de la corona.- 5. Bibliografía citada.

La monarquía castellana se involucró en la promoción de las órdenes mendicantes al poco de su llegada a la Península ${ }^{2}$. Además de brindar muestras de favor general a los enteros institutos religiosos, siguió una política selectiva y matizada, muy visible en la variedad de formas de impulso y de apoyo adoptadas, así como en la preferencia por conventos y monasterios concretos. Fueron diversos los acentos de la actuación regia: desde la formulación de la voluntad de fundar nuevos establecimientos hasta la puesta en ejecución de los procesos fundacionales, pasando por el apoyo a los que ya estaban en marcha, la concesión de privilegios, donaciones, exenciones o distintos tipos de favores. Diversa fue también la implicación de los miembros de la familia real. Ello se correspondió con intereses y vínculos heterogéneos y su análisis ofrece una interesante cantera informativa de la política religiosa de la corona.

Resulta de gran interés su relación con los monasterios de monjas. Son cuestiones pendientes de estudio, pero hay indicios de fenomenologías sexuadas en la implantación mendicante femenina. Los reyes, ciertamente, pudieron apoyar y respaldar con donaciones y privilegios fundaciones de monjas que otros agentes creadores ya habían puesto en marcha con anterioridad y, en algún caso, brindar la ayuda decisiva para que algunas comunidades lograran afianzarse. Sin embargo, en el amplio marco fundacional mendicante femenino de la Corona de Castilla fueron pocos los monasterios cuyo origen decidieron y llevaron a su plena ejecución. Además, los monarcas parecen haber reservado su impulso y favor más intensos a las dominicas en contraste con las mujeres de la familia real, en principio más inclinadas por las religiosas relacionadas con Clara de Asís ${ }^{3}$. En cualquier caso, los monasterios de franciscanas en cuya génesis participaron los titulares de la corona se inscriben en un tipo característico de "fundación en relación".

Este trabajo se inscribe en el proyecto de investigación I+D+I Claustra. Atlas de espiritualidad femenina (HAR 2011-25127). Agradezco la generosa acogida de la comunidad de Santa Clara de Astudillo, que me permitió trabajar en su archivo en julio de 2013. Monjas valerosas que tanto han luchado por mantener en pie su monasterio y, con él, la memoria de doña María de Padilla y Pedro I.

2 J. García Oro, Francisco de Asís; P. Linehan, La Iglesia, entre otros.

3 J. García Oro, Francisco de Asís; P. Martín, Sobre la promoción; M ${ }^{a}$ M. Graña, Reinas. 
Así, o bien se sirvieron de intermediarios para fundar ${ }^{4}, \mathrm{o}$, sobre todo, actuaron en colaboración con mujeres. Al estudio de esta segunda forma de obrar se consagran las siguientes páginas.

En ella se encuadran algunas fundaciones promovidas por Alfonso X y Pedro I. Si bien conocemos la participación del Rey Sabio con su esposa doña Violante en el origen de comunidades como la que con el tiempo sería Santa Clara de Murcia o, según tradiciones, Santa Clara de Santiago de Compostela, se trata de procesos ensombrecidos por la parquedad informativa ${ }^{5}$. En cambio, las fuentes muestran con nitidez la colaboración de los monarcas con sus amantes o las hijas fruto de su unión al objeto de promover monasterios de la Orden de Santa Clara o de sus formas institucionales previas. Analizaremos esta segunda casuística buscando conocer las políticas fundacionales a fin de valorar lo institucional y lo personal, los intereses masculinos y femeninos en coincidencias y/o diferencias, así como los vínculos relacionales que las sostuvieron y que propiciaron. Pretendemos también perfilar las fisonomías de los cenobios que constituyeron la institución clarisa, una orden religiosa exclusivamente femenina donde las mujeres tuvieron gran peso específico como agentes históricos. Estas páginas constituyen un primer avance a la espera de profundizar más adelante en otros tipos fundacionales y poder extraer conclusiones comparativas.

\section{PROCESOS FUNDACIONALES Y TIPOLOGÍAS MONÁSTICAS}

Tres monasterios ofrecen noticias seguras: Santa María de San Miguel del Monte (Guadalajara), transformado al cabo de los años en Santa Clara de Alcocer; Santa Clara de Astudillo (Palencia) y Santa María de Tordesillas (Valladolid).

${ }^{4}$ La Andalucía de la restauración cristiana podría brindar la clave. Los reyes impulsaron la implantación clarisa de forma preferente, pero sólo está bien documentado Santa Clara de Córdoba, cuya fundación fue encomendada por la corona a un tercero. En los demás, la intervención regia está nublada por la leyenda y no es posible precisar fenomenologías fundacionales o iniciativas directas. J.M ${ }^{\mathrm{a}}$ Miura, Frailes, pp. 141-151; M ${ }^{\mathrm{a}}$ M. Graña, Las primeras clarisas, pp. 677-678.

${ }^{5}$ ¿Acaso porque la intervención de la pareja regia fuese limitada de algún modo? Además, no hay datos sobre su actuación en Santiago. Sí es muy completa la información sobre el cenobio que fundó la reina, Santa Clara de Allariz. J. García Oro, Francisco de Asís, pp. 234 , 446-447, 122, 133-139. 


\subsection{Santa María de San Miguel del Monte: Mayor Guillén de Guzmán y Alfonso X}

Esta fundación fue protagonizada por doña Mayor Guillén de Guzmán. Amante de Alfonso X cuando todavía era infante, tuvo con él una hija, Beatriz, futura reina de Portugal. Se efectuó tras el acceso al trono de don Alfonso y el nacimiento del primer fruto de su matrimonio con la reina doña Violante. Doña Mayor la efectuó por razones expiatorias y penitenciales: la salud de su alma e en remisión de míos pecados, sin establecer vínculo expreso con su familia ni con la corona.

Si las crónicas datan el origen del monasterio en $1252^{6}$, doña Mayor no otorgó el documento de dotación hasta 1260. Estudiosos recientes señalan que hubo un proceso fundacional que, de dar credibilidad a las tradiciones, pudo iniciarse en 1252 y que finalizó en 1260 , aunque ya en 1259 el monasterio estaba edificado y habitado ${ }^{7}$. De esta última fecha son los primeros documentos, tres bulas de Alejandro IV. Les siguió la dotación de doña Mayor en septiembre de 1260 y la donación otorgada por su hermano, el adelantado mayor de Castilla Pedro de Guzmán, en octubre. Ambas fueron confirmadas por el rey: la primera en noviembre de ese mismo año y la segunda en marzo del siguiente. Dos bulas de Urbano IV afianzaban la fundación y su fisonomía institucional en $1262^{8}$.

Se trató de un monasterio de la Orden de San Damián, una creación del papado que tomó el referente nominal del lugar de habitación en Asís de Santa Clara y sus compañeras aun planteando un proyecto religioso muy distinto al ideal evangélico de la santa. Pero es preciso hacer notar que lo contradictorio de algunas noticias suscita dudas sobre su fisonomía institucional. En 1259, esta comunidad era damianita y se denominaba indistintamente monasterio de Alcoçer, Santa Clara de Alcocer y Sancti Michaelis de Alcoçer. Sin embargo, en la escritura de dotación de 1260 la fundadora decía que es dicho de Santa Maria d'Alcocer y que era de menoretas de la Orden de Sant Francisco. ¿En posible referencia a la regla promulgada por Inocencio IV en 1247 o bien a la regla de Longchamp, escrita por impulso de la familia real francesa para las "hermanas menores encerradas" y recién promulgada por el papa Alejandro? Ambas vinculaban a las religiosas a los franciscanos y sobre todo en la segunda era importante el referente mariano; su difusión estuvo muy conectada con la

${ }^{6}$ P. M. Ortega, Chrónica, p. 29; P. Martín, La fundación, pp. 230-231; idem, El monasterio.

7 Véase el detallado seguimiento de P. Martín, La fundación, p. 232, notas 12-16.

8 AHN, Clero, 566/2, 4 y 5; 568/16; Sellos, 55/4; Archivo Municipal de Alcocer, libro A1, f. 203r-v; P. Martín, Colección, no 3-5, 7-10, pp. 168-174; P. Martín, La fundación, pp. 240-241. 
realeza y se ha sospechado que Alfonso X pudo estar interesado en implantarla en Andalucía por esas mismas fechas ${ }^{9}$. Podría ser sintomático que doña Mayor señalase que fundaba el monasterio a honra de Dios, Santa María e de Sant Francisco, sin mencionar a Santa Clara. Sin duda lo es que no mencionase a la Orden de San Damián. Aunque pueda pensarse en un posible uso indistinto de términos, estas denominaciones solieron corresponderse con realidades institucionales diferentes que se mantuvieron pertinaces en el tiempo: todavía en 1295, Bonifacio VIII se dirigía a las religiosas siue ordinis Sancte Clare siue Sancti Damiani seu minorisse dicantur ${ }^{10} \mathrm{y}$, de hecho, este monasterio de Alcocer no se integraría en la Orden de Santa Clara hasta el siglo XIV.

Fueron los papas quienes desde el principio presentaron al cenobio como damianita y se preocuparon por afianzar esta identidad canónica. Tal hizo Urbano IV en 1262. ¿Por un posible "estado de indecisión” institucional en los primeros años? No deja de ser llamativo que estableciese la observancia inviolable a perpetuidad de las bases normativas de la Orden de San Damián: la regla de San Benito y las constituciones del cardenal Hugolino de Ostia, como si fuese necesario enfatizar y reforzar su observancia. Cierto que sus disposiciones reflejan también un estado de abusos externos y dificultades que estaban mermando la vida religiosa y que quizá hicieron necesaria dicha ratificación.

Varias características de este monasterio eran potencialmente problemáticas. Una fue su condición privilegiada: en 1259, Alejandro IV lo declaraba exento del pago de diezmo. Otra fue su vínculo directo con la Sede Apostólica: este papa lo establecía al disponer que nadie pudiera obligar a la comunidad a recibir nuevas monjas sin mandato pontificio y Urbano IV lo fortalecía después al conceder especial protección apostólica al monasterio y su patrimonio. Afianzaba también la libertad, tanto en la admisión de nuevas candidatas como en la elección de la abadesa, así como la clausura, el sistema de propiedad común y el vínculo eclesiástico diocesano. Respecto a este último, establecía que el obispado de Cuenca había de prestarle todos los servicios religiosos gratuitamente. Los problemas debieron proceder de la diócesis, a la que quizá resultó difícil hacerse cargo de las monjas respetando sus privilegios.

El tercer rasgo destacable y que favoreció los abusos fue el no ubicarse en Alcocer, sino en un despoblado cercano. Pablo Martín Prieto se ha preguntado si el monasterio no pudo surgir de un beaterio de espiritualidad franciscana nacido al calor del legendario viaje de San Francisco de Asís a

${ }^{9}$ G. Duchesne, Histoire; Mà. Graña, Las primeras, pp. 696-698.

${ }^{10}$ AMA, libro A1, f. 204r; P. Martín, Colección, no 25, pp. 185-186. 
la Península y, acaso, en torno a algún tipo de ermita o espacio de culto franciscano en la zona. Relaciona esta tradición con las noticias que remiten a discípulas de Santa Clara como fundadoras, que acaso crearon en 1252 un establecimiento damianita a partir del beaterio ${ }^{11}$. Sin negar esta posibilidad, también cabría admitir lo que defienden algunos cronistas: que fue la propia doña Mayor quien solicitó damianitas fundadoras a Santa Clara ese año. En cualquier caso, los emplazamientos eremíticos -cerca de núcleos habitadosfueron característicos de la Orden de San Damián. De ello da cuenta su implantación hispana.

No es posible precisar las dimensiones de la comunidad, aunque los datos apuntan a una posible amplitud: doña Mayor establecía un límite de cien personas entre monjas, hombres y mujeres, e que no puedan más seer, sin especificar un "numerus clausus" monástico. Por otro lado, este monasterio no se constituyó como entidad señorial aun cuando gozase de parte del patrimonio que conformaba el señorío creado por el rey para doña Mayor y en el que se incluían varias rentas de procedencia realenga. La fundadora se preocupó por fijar bien los límites y preservar la integridad de dicho señorío ordenando que la comunidad no pudiera comprar ni ganar más de lo que les daba en sus lugares de Alcocer, Viana, Cifuentes y Palazuelos $^{12}$. Desde un punto de vista administrativo, el cenobio nacía condicionado por las directrices que ella imponía, tanto en el límite numérico del contingente humano como el reparto de las rentas y el destino específico de ciertas partidas.

Por último, señalar que la fuerte impronta pontificia del monasterio de Santa María no tuvo paralelo regio, pues Alfonso X, pese a ser también su impulsor, no le otorgó privilegios especiales. Antes bien, se limitó a confirmar todo lo dispuesto por doña Mayor y, años después, lo favoreció con alguna nueva concesión económica, pero en línea similar a las de otros cenobios.

\subsection{Santa Clara de Astudillo: María de Padilla y Pedro I}

Un siglo después encontramos otra situación similar. Doña María de Padilla, amante de Pedro I, fundó el monasterio de Santa Clara de Astudillo entre 1353 y 1356. El inicio de la fundación coincidió con la boda del rey con Blanca de Borbón.

\footnotetext{
${ }^{11}$ P. Martín, La fundación, pp. 233-234.

${ }^{12}$ Sobre el patrimonio fundacional: F.J. Villalba, Propiedad; idem, El monasterio; P. Martín, Formación.
} 
Las noticias comienzan con las licencias eclesiásticas, del obispado de Palencia en noviembre de 1353 y del papado en abril de $1354^{13}$, cuando todavía no se había decidido el lugar exacto. Inocencio VI otorgaba tres bulas permitiendo fundar un monasterio para cincuenta monjas -contando a la abadesa- de la Orden de Santa Clara, ya constituida. A aquellas alturas del siglo XIV, ello implicaba la jurisdicción franciscana y la consiguiente integración del monasterio en la provincia minorítica de Castilla. Estos documentos revelan la preocupación de doña María por crear una comunidad con buen nivel religioso, para lo cual suplicaba al papa poder elegir en los monasterios de clarisas del reino diez monjas literatas, devotas de Dios y eruditas en la observancia, además de seleccionar como primera abadesa a la que viere más idónea y útil. El pontífice otorgaba su licencia incluso aunque contrariase las constituciones de la orden y le permitía entrar libremente en los monasterios castellanos de clarisas una vez al año con tres o cuatro matronas honestas para informarse de las ceremonias, reglas y observancias, pero sin poder comer ni pernoctar allí.

Se trabajó seguidamente en la constitución material ${ }^{14}$. Elegido Astudillo, doña María encargó señalar el sitio e iniciar la edificación del monasterio a su mayordomo Juan González de Pedrosa y a fray Juan de Balbás. Tras desechar un primer emplazamiento intramuros por poner en peligro la clausura de las monjas su excesiva cercanía a la iglesia, acordaron erigirlo junto a la población, en el llamado Pozo Bueno. No podemos precisar fechas, pero en febrero de 1355 doña María ya había elegido abadesa, doña Juana Fernández de Henestrosa, y ésta protagonizaba una intensa actividad de compras ${ }^{15}$.

Ese año se establecieron las bases económicas de la fundación y se documenta la intervención del rey, que comenzó a otorgar importantes participaciones en rentas de la corona. En abril, don Pedro concedía 5.000 maravedís anuales en el portazgo de Burgos y, si no rentare lo suficiente, en la aljama de los moros. En junio, doña María entregaba una primera dotación y en diciembre adquiría objetos litúrgicos para la comunidad. Como novedad respecto a Alcocer, conformaba un monasterio señorial al ceder a las monjas su lugar de Cubillas de Cerrato con toda su jurisdicción, pechos, derechos y vasallos, y todos sus bienes en Astudillo, aunque pretendía dar más. Casi un año después,

13 ASCA, leg. 1/3 y 1; L. Waddingo, Annales, vol. VIII, núms. XXI, XXII y XXX, pp. 525-26 y 531; F. Simón, El monasterio, no 1-3, pp. 137-140.

${ }_{14}$ Véase el análisis del dominio del monasterio efectuado por I. Álvarez, Órdenes mendicantes, pp. 561-567.

15 ASCA, caja 1; leg. V, caja 11, con diversos pergaminos a partir del $n^{\circ} 3$; F. Simón, El monasterio, $\mathrm{n}^{\mathrm{O}}$ 30, p. 161. 
en febrero de 1356, completaba su actuación al otorgar el documento de dotación-fundación solemne. Aquí, como en Alcocer, figuraba la administración comunitaria condicionada por el dirigismo de la fundadora, que estipulaba la distribución exacta de la renta y el número de integrantes del complejo monástico. Habían de ser cuarenta personas -frente a las cien de Alcocer-: treinta monjas, dos frailes y ocho servidores, de los cuales seis varones y dos mancebas. También señalaba el pan necesario para un par de acémilas y para los frailes y clérigos que fuesen con bestias a los aniversarios o a visitar. El dinero lo repartía con distintos fines, coincidiendo con doña Mayor en su preocupación por la enfermería: así, para carne y pescado para las monjas, dos capellanías y tres aniversarios anuales, varias lámparas, cera, fiestas, aniversarios, alumbrar el cuerpo de Dios, vestuario, para cada monja que enfermare, para cada enfermerica y para cavar las viñas cada año. Cumplido todo, calculaba que al año sobrarían 1.384 maravedís que deberían guardar junto a lo que sobrase del pan para hacer frente a los malos tiempos, pues el monasterio se mantendría si bien regidas fuesen las dichas rentas ${ }^{16}$.

Este año 1356 no fue sólo el de la culminación fundacional. También se perfiló la fisonomía privilegiada del monasterio de Astudillo, paso previo hacia la total constitución como entidad señorial en 1359. El mes de marzo de 1356 fue clave: se conserva un número importante de privilegios otorgados por los poderes político y eclesiástico y acaso de común acuerdo, pues se redactaron en el mismo sitio, Tordesillas. El rey señaló las cuestiones que después el legado papal ratificó a petición de las monjas y de doña María, deseosas de asegurar el apoyo de la Iglesia a las concesiones del monarca.

Abría camino Pedro I con cuatro documentos de gran importancia material en los que, además de confirmar las donaciones de doña María y las gracias temporales del papado, sumaba nuevas mercedes confiriendo al monasterio un perfil privilegiado. Facultaba la ampliación de la base patrimonial y la diversificación de su estructura con dos concesiones. Una, la adquisición de ganados: podrían tener cuarenta vacas, tres mil ovejas y cabras y doscientos puercos con libre pasto en todo el reino. Otra, la libertad de recepción de bienes: les permitía heredar de sus padres y parientes -en línea directa o traviesa- y recibir donaciones y legados según los fueros y costumbres de las villas y lugares. Además, iniciaba la formación de un grupo clientelar al conceder cincuenta excusados para labrar sus fincas o guardar sus ganados que las monjas podían tomar en los lugares que doña María les

16 ASCA, leg. 2/12, 3 y 1; leg. IV/1; AHN, Clero, 1689/12; leg. 5312; F. Simón, El monasterio, $\mathrm{n}^{\circ}$ 14, 16-17 y 58, pp. 149-158 y 177-178; L. V. Díaz Martín, Colección, vol. 3 , $\mathrm{n}^{\circ} 922$, pp. $251-253$. 
había dado o les diere y, de no haberlos, en Astudillo o en la merindad de Castrojeriz $^{17}$.

El 21 de marzo era la autoridad eclesiástica, representada por el cardenal Guillermo de La Jugie como legado papal en Castilla ${ }^{18}$, quien otorgaba un paquete de seis documentos muy centrados en lo material. Con tres de ellos ratificaba el carácter privilegiado del monasterio en lo económico. Confirmaba los ya otorgados por el rey para garantizar el sustento -sobre los exentos y los ganados-, así como la dotación de doña María y su reparto. Daba gran importancia a la capacidad de herencia de las monjas, reconocida en documento aparte, y a los posibles abusos y violencias en otro. También añadía nuevos privilegios eclesiásticos, incluso por encima de la normativa canónica: declaraba patrona a doña María y limitaba la capacidad de intervención de la Orden de San Francisco y de la autoridad eclesiástica. En un documento establecía que el provincial franciscano estuviese obligado, cuando a ello fuese requerido por doña María como patrona, a designar dos visitadores y un confesor. En otro, que ninguna autoridad eclesiástica pudiese trasladar monjas de este monasterio a otro de la orden a no ser por causa probada legítimamente o con el consentimiento de la abadesa. Por último, daba facultad para permutar bienes con el obispo y cabildo de Palencia ${ }^{19}$.

El rey concedía más mercedes entre 1356 y 1359 con las que el cenobio completó su incipiente perfil señorial. Siguió transfiriendo rentas a la comunidad cediendo la martiniega de Matanza y su parte en la de Palencia -que era la mitad- y permitió traspasar la de Astudillo. De ello se ocupó su hija mayor Beatriz en 1359 con licencia y mandato de sus dos progenitores, pues era muy niña; doña María consentía en la acción, ordenaba al concejo que lo cumpliese y firmaba el documento, mientras don Pedro lo confirmaba. Pero, sobre todo, el monarca reforzó esta dimensión señorial local cuando, el mismo día, permitía a las monjas tener dentro de su cerca treinta vasallos. Estarían exentos de todo tributo los diez primeros años y después pecharían al monasterio salvo la moneda forera, que seguiría cobrando el rey. Habían de ser de Astudillo o de sus barrios y, si viniesen de otros lugares, pagarían además 500 maravedís ${ }^{20}$.

17 AHN, Clero, 1689/14-15; ASCA, caja 2-II-5; leg. 2/4, 6 y 7; A. Orejón, Historia, no 4, pp. 140-142; F. Simón, El monasterio, ${ }^{\circ}$ 18, p. 158; L.V. Díaz Martín, Colección, vol. 3 , no 977-978, pp. 288-289.

18 J. Zunzunegui, La legación, p.145.

19 ASCA, leg. 1/10, 11, 7, 24, 8, 9 y 5; A. Orejón, Historia, no 5, 6, 7, 9-11, pp. 142-154; F. Simón, El monasterio, no ${ }^{\circ}-5$, pp. 141-142.

20 ASCA, leg. $2 / 6$ y 17; referencia en papel sin clasificar; leg. 2/9 y 10; AHN, Clero, leg. 5312; F. Simón, El monasterio, $\mathrm{n}^{\circ}$ 20, p. 159; A. Orejón, Historia , ${ }^{\circ}$ 12, pp. 154-155; L.V. Díaz Martín, Colección, vol. 3, nº 1.034 y 1.076, pp. 341-342 y 379-380. 
Éste fue el único monasterio con puebla de vasallos de los aquí estudiados. A una tercia entre Astudillo y el monasterio, estaba separada por una cerca donde había una puerta llamada de Santa Clara -cuyas llaves tenía la abadesa- por donde entraban y salían los vasallos de las monjas sin necesidad de pasar por la población. La puebla contaba con gobierno y jurisdicción propios. Los vecinos constituían concejo aparte y hacían su ayuntamiento en el cenobio. La abadesa, en su calidad de señora, elegía al alcalde y al merino; además, había prisión propia ${ }^{21}$. Quedaba así definido un monasterio con destacadas competencias señoriales y un notorio perfil de privilegio, tanto económico como eclesiástico, con importantes cotas de autonomía en su funcionamiento, y que nacía con un objetivo de mejora de la vida religiosa.

Por otra parte, coincidiendo con San Miguel del Monte, recibía de su fundadora un marcado carácter expiatorio personal con el que mostraba su conciencia de pecado por su relación con el rey. En el amplio preámbulo teológico del documento de dotación, María de Padilla afirmaba que el hombre, para intentar conocer a Dios, ha de fijarse en lo altos, santos y maravillosos que fueron sus hechos y en las cosas santas que cada día suceden. Añadía una referencia a lo natural del pecado por no haber criatura en el mundo que no errase o pecase. Puesto que el remedio es el arrepentimiento, la penitencia y hacer el bien, cosas que placen mucho a Dios, y puesto que creía verdaderamente en su piedad y era muy consciente de su pecado, había deseado hacer algún bien, maguer quel bien non sea tan grande como el de mi error, que Dios que avrá merced e piedad de la mi alma e de la mi vida. Por ello, había hecho el monasterio de Astudillo, intención que le vino de Dios, en el que tenía fe. Sin embargo, difería de Mayor Guillén en el hecho de querer vincular su fundación a la persona del monarca favoreciéndole con el beneficio de mediación espiritual; además, hacía copartícipes a sus consanguíneos en lo que constituía una referencia familiar que estuvo ausente de las disposiciones fundacionales de Alcocer. En efecto, instituía dos capellanías y tres aniversarios anuales compuestos por treinta misas cada uno que debían ser celebradas por veinte clérigos y diez frailes con la finalidad de rogar a Dios por la vida del rey, por el alma de su padre y de sus parientes fallecidos, así como por ella, que me dé buen acabamiento ${ }^{22}$.

${ }^{21}$ El vínculo con los vasallos fue también religioso: una de ellos, Juana García, disponía en 1362 ser enterrada en la iglesia del monasterio con hábito de clarisa y lo declaraba heredero del remanente. ASCA, caja 1; leg. 3/11.

${ }^{22}$ ASCA, leg. 2/1; AHN, Clero, leg. 5312; F. Simón, El monasterio, nº 17, pp. 153-154. 


\section{Pedro I}

\subsection{Santa María de Tordesillas: las infantas Beatriz e Isabel y}

La hija mayor de María de Padilla y Pedro I, Beatriz, reconocida por su padre infanta heredera de Castilla en las cortes de Sevilla de 1362, protagonizó con el apoyo de su hermana Isabel y el respaldo del rey una nueva fundación al poco de fallecer su madre. Ambas eran niñas de nueve y siete años. En realidad, la voluntad había partido del rey, que en su testamento del 18 de noviembre de 1362 ordenaba fundar a su hija ${ }^{23}$. El proceso fue rápido: iniciado el 2 de enero de 1363, culminaba ese mismo año. Los tres implicados en la fundación suscribían diferentes documentos de contenido, en buena medida, complementario, escritos el mismo día y en el mismo lugar, Sevilla ${ }^{24}$, interesante manifestación de esta tipología relacional.

Doña Beatriz cumplía órdenes de su padre en su pretensión de erigir en sus palacios de Tordesillas un monasterio con la advocación de Santa María para treinta monjas de la Orden de Santa Clara y un número indeterminado de clérigos y servidores. La fundación nacía con un componente señorial más marcado que el de Astudillo. Recibía como dotación todos los pechos, fueros y derechos -yantar, martiniega, portazgo, infurciones, escribanía, caloñas, tablajería, cabeza de los judíos y entregas de los judíos- y todas las heredades -tierras, viñas, casas, aceñas, zumacales y otras cosas- que la infanta tenía en Tordesillas y sus aldeas salvo el señorío y los otros pechos reales. Además, doña Beatriz cedía el señorío pleno sobre su bailía de San Miguel del Pino con San Martín del Monte y Torrecilla, todos sus lugares, vasallos, heredades, montes y guardas. Las monjas podrían poner alcaldes, merinos, escribanos y otros oficiales en todos esos lugares ${ }^{25}$.

También en este caso la fundadora intervenía en la definición religiosa de su creación, que nacía con un grado de autonomía respecto a la Orden de San Francisco todavía mayor que Astudillo, pero con un planteamiento similar de mejora interna. Así, determinaba que los bienes se pusiesen en común y ninguna monja tuviese propio. Además, intervenía en la organización de la jornada y la administración. Las monjas no debían labrar desde la mañana hasta tercia para estar continuamente en oración y en los oficios divinos. Por otra parte, la administración espiritual y temporal debían

23 J.B. Sitges, Las mujeres, p. 259; AGP, Registros, n 5587: Libro de bezerro..., 1713, vol. I, f. 42.

${ }_{24}$ AGP, caja 4915/2; ASCT, caja 30/3; 44/1. J. Castro, Colección, núms. 92-94, pp. 76-86; L.V. Díaz Martín, Colección, vol. 4, n ${ }^{\circ} 1.205$, p. 115.

${ }^{25}$ Véase el detallado análisis de estos privilegios de jurisdicción efectuado por S. Rodríguez, El monasterio, pp. 82 y ss. 
recaer en fray Juan de Balbás mientras viviese; si de lo espiritual había de hacerse cargo directamente, en lo temporal debía asignar persona o personas para ello. La infanta establecía un vínculo expreso con la corona por encima de la jurisdicción eclesiástica, pues, tras la muerte del fraile, la competencia administrativa recaería en quienes designasen el rey Pedro y sus sucesores.

La infanta Isabel añadía a la dotación Aldeamayor y sus salinas y después intervenía el rey confirmándolo todo. Señalaba que había dado autoridad y licencia a sus hijas y participaba en el diseño modificando algunas disposiciones de su heredera. Establecía que debía haber siempre seis capellanes obligados a cantar una misa todos los días de buena mañana según el ordenamiento que dispusieran la abadesa y monjas; después, a la hora de tercia, las monjas debían cantar la otra misa del convento. Otorgaba más protagonismo a fray Juan de Balbás en la administración de la hacienda monástica, disponiendo que se hiciese por su consejo y consentimiento mientras viviese. Modificaba lo establecido por su hija desvinculando esta función de la corona porque, tras la muerte del fraile, la responsabilidad administrativa debía recaer en la abadesa y monjas o en quien ellas decidiesen con consejo del visitador. Y, por último, responsabilizaba al obispo de Palencia de la puesta en marcha de la fundación.

Los últimos hechos relevantes de ese año fueron dos. Primero, la concesión de licencia por el obispo el 5 de febrero. Don Gutierre Gómez disponía que las monjas pudiesen situar en la iglesia los altares que viesen que cumplían y con las advocaciones que deseasen, así como todas las cosas que les pareciese quedando a salvo el derecho de la iglesia palentina. Segundo, apoyando el proceso fundacional, don Pedro otorgaba en agosto seis excusados -mayordomo, carpintero, cantero, acemilero y dos montanerosque habían de elegir las monjas en la villa de Tordesillas y, si no encontrasen allí cantero y carpintero, podían buscarlos donde quisieran. Estos excusados no estarían obligados a ir a los llamamientos en tiempo de guerra. Aunque ya debía haber comunidad establecida, las noticias más directas se documentan en septiembre ${ }^{26}$.

Sin embargo, las bulas papales se hicieron esperar casi dos años. El 27 de febrero de 1365, Urbano V destinaba un paquete de tres mientras al tiempo dirigía otro a Santa Clara de Astudillo. Confirmaba la fundación y los privilegios otorgados por el rey y situaba al monasterio y su dotación bajo la protección y amparo de la Sede Apostólica ${ }^{27}$.

${ }^{26}$ ASCT, caja 6/1; caja 1/2; AGP, Registros, no 5587: Libro de bezerro, vol. I, ff. 122-124; AGP, S/H, caja 343/2; M. González, Inventarios, ${ }^{\circ}$ 12; J. Castro, Colección, no 96, pp. 87-88; L.V. Díaz Martín, Colección, vol. 4, n 1.231, p. 133.

${ }^{27}$ ASCT, caja 6/2, 3 y 4; AGP, caja 4915/2; Registros, n 5587: Libro de bezerro, vol. I, f. 46. 
Esta fundación no puede separarse del momento difícil por que atravesaban la persona y el reinado de Pedro I ni de su deseo de legitimar a una de sus ramas bastardas. Son de gran interés los largos preámbulos teológicos con que se inician los tres documentos fundacionales. A diferencia de Alcocer y Astudillo, no se exponen aquí argumentos expiatorios y lo que se subraya es la función salvífica y mediadora del monasterio respecto a la concreta realidad que sus promotores estaban viviendo. Si bien los tres documentos coinciden en algunos temas, en otros siguen un tenor diferenciado que los hace complementarios: cada uno aporta una faceta diferente de la cuestión, muy relacionada con la concreta acción que, en el marco de la promoción fundacional, refleja.

El documento principal, que era la carta de fundación expedida por la infanta heredera, desarrollaba los argumentos centrales: el carácter benéfico de la oración, la capacidad de las oraciones que otros rezan por quienes se las encargan y la mayor facultad de las personas religiosas para obtener gracia de Dios. De la oración se obtienen tres grandes bienes: la salvación de las almas, la salud de los cuerpos y la prolongación de la vida y la victoria sobre los enemigos, espirituales y terrenales. Cada uno de estos beneficios se fundaba en palabras de autoridad: el primero con argumentos del apóstol Santiago y San Agustín; el segundo por testimonio de Inocencio III al relacionar la enfermedad del cuerpo con la del alma y la bondad de la oración, además de otras muchas autoridades que se habían referido a la prolongación de la vida, entre ellas Isaías; el tercero se apoyaba en Moisés y en figuras históricas como el emperador Teodosio el Viejo. Sin embargo, añadía, para que las oraciones sean bien oídas y recibidas por Dios son necesarias dos cosas: personas que las hagan y lugar en que se hagan. Tales personas debían ser bien aparejadas para ello e que ayan contriçión e que estén en verdadera penitencia, porque, según la Escritura, cuanto más dignos sean los orantes, tanto más serán sus oraciones oídas y recibidas en los monesterios de aquellos por que las fasen; de hecho, según San Gregorio primero se fija Dios en la persona que ora y después en lo que ora. Además, las oraciones han de hacerse principalmente en las iglesias y monasterios porque en estos lugares cresçe más la deuoçión, huyen de ellos los espíritus malignos al no poder tentar a los que rezan y hay reliquias, lo que garantiza que son mejor oídas y recibidas, algo que también afirmaba San Bernardo.

Pasaba a exponer después la aplicación concreta de estos argumentos generales: pretendía que la oración de la comunidad religiosa alcanzase la gracia de Dios en la resolución de los graves problemas que aquejaban a Pedro I. Allí se había de rezar por la vida y salud del rey, para que aya victoria contra todos los sus enemigos, así terrenales como spirituales y por la salvación de su alma. Se trataba además de que la nueva familia real, a la que don 
Pedro acababa de legitimar en cortes, recibiese refrendo simbólico. Así, doña Beatriz especificaba que las oraciones debían ser también por las almas de sus familiares difuntos: por su hermano el malogrado infante don Alfonso, fijo primero heredero del dicho señor rey, por su madre María de Padilla, a la que denominaba reina, así como por su propia vida y salud. Ello se concebía en clave mariológica y femenina. La infanta heredera subrayaba el papel central de la Virgen, plasmado en la advocación de la casa y en la intención última que animaba el proyecto. Afirmaba que su padre y ella sentían gran devoción por la Madre de Dios y expresaba su deseo de que rogase a Dios por los problemas señalados. En la tierra lo habían de hacer las monjas, en este caso no sólo a Dios, sino también a la propia María. La infanta, al establecer esta doble vía femenina de mediación orante, repetía dos veces las finalidades de las oraciones que solicitaba, una insistencia que, probablemente, no es casual. Mediación orante femenina que se creía poderosa y que reconocía a la palabra de las mujeres capacidad de hacerse oír y responder por Dios.

La infanta Isabel añadía a estos argumentos centrales la cuestión de las buenas obras: toda buena obra que se comienza bien y con recta intención y devoción ha de gozar de ayuda para culminar, en especial las de piedad. Quien colabore en ello habrá de ser aparcero de todo el bien y alcanzar su parte del merecimiento y galardón, porque, según la Escritura, no hay bien que quede sin recompensa. Para San Jerónimo, todas las limosnas que se hacen a las iglesias o a los monasterios implican que sus servidores están obligados a rogar a Dios por aquellos e aquellas de quien por quien las resçiben. De ahí su decisión de intervenir apoyando a su hermana, cuya intención era santa, devota y cumplidora para la vida, salud y estado del rey y de las almas de su hermano y de su madre. Además, puesto que deseaba ser aparcera de dicho bien y eso implicaba que las monjas estarían más obligadas a rogar a Dios y de hacerlo más afinadamente, añadía bienes a la dotación. Al hacerlo, insistía en las finalidades principales: loor y servicio de Dios, la Virgen y todos los santos del paraíso; que su padre obtuviese victoria contra todos sus enemigos y salvación para su alma, así como también por las almas de su madre y hermano y por su propia vida y salud.

Finalmente, el rey completaba la argumentación teológica afirmando que, según la Escritura, pertenece al rey católico y al buen príncipe hacer fundar iglesias y defenderlas porque en ellas es loado el nombre de Dios, al que deben servir todas las gentes. Los reyes lo deben adorar y loar señaladamente para que eso suceda, tal como dijo el profeta David, quien además afirmó que Dios da salud a los reyes y los libra y defiende de los peligros de este mundo. Puesto que los derechos acuerdan que lo que se hace en presencia del rey se entiende ser cumplido con toda solemnidad porque, según los sabios, todas las cosas a las que el rey dé su autoridad se hacen suyas como si él mismo 
las hiciese, confirmaba lo que acababan de hacer sus hijas y lo hacía ser suyo propio. Sin embargo, no mencionaba las dificultades por que atravesaba ni pedía victoria sobre sus enemigos. Antes bien, la función espiritual de aquella fundación era la oración por las almas de su heredero y de la reina doña María, su mujer, así como por la vida, salud, honra y estado de sus hijas.

\section{LA FUNDACIÓN MONÁSTICA COMO VÍA DE EMPODERAMIENTO FEMENINO}

Los casos revisados tuvieron en común el protagonismo de las mujeres como fundadoras, constructoras y dotadoras de los monasterios aunque contasen con el respaldo de los reyes o, incluso, pudiesen ser ellos los responsables de la voluntad fundacional. Dar origen a un monasterio de la Orden de Santa Clara parecía entenderse como una empresa femenina.

Se percibe una acusada dimensión personalista. Las fundadoras "hacían" los monasterios y así era admitido por todos. Los documentos registran afirmaciones contundentes: María de Padilla se refería al monasterio que yo fago y los canónigos de Palencia afirmaban que era voluntat de la dicha doña María de facer un monesterio. Mayor Guillén "hacía" su monasterio y una criada suya recordaba que ésta fizo el monasterio de Alcocer o que era fechura suya. Quizá por ser niñas, las infantas Beatriz e Isabel no se expresaban de forma tan directa, pero no por ello dejaban de indicar la responsabilidad última: Beatriz mostraba su entençión de dar e facer consagrar las mis casas principales y su hermana favorecía al monasterio que aquélla "mandó hacer" 28 . Las fundadoras, además, aportaban las bases materiales necesarias con su patrimonio personal y subrayaban que hacían los monasterios de bonis propriis ${ }^{29}$. Ello implicaba también que se refiriesen a ellos como "mi monasterio".

Por otra parte, tenían vínculos personales con los lugares de fundación, como haber nacido o vivido allí. Si doña Mayor Guillén pudo empezar a residir en Alcocer en 1252, los documentos pontificios hacen a María de Padilla oriunda de la diócesis de Palencia y una opinión muy extendida defiende que nació en Astudillo. No fue el caso de la infanta Beatriz, nacida en Córdoba, pero sí de su hermana Isabel, que había visto la luz en el palacio de Tordesillas. Igualmente, se trataba de lugares donde tenían previos intereses patrimoniales

28 ASCA, leg. 1/3 y 7; F. Simón, El monasterio, núms. 1, 2 y 16, pp. 138-139 y 151; A. Orejón, Historia , no 6, pp. 147-149; ASCT, caja 30/3; AHN, Clero, 566/18; P. Martín, Colección, $\mathrm{n}^{\circ}$ 21, pp. 182-183.

${ }^{29}$ AHN, Clero, 1689/11; A. Orejón, Historia, no 5, p. 143; P. Martín, La fundación, p. 232, notas 12-16. 
con su familia. Esto es claro cuando habían nacido allí y en el caso de doña Mayor cabe pensar que posiblemente también sus parientes tuviesen bienes en Alcocer antes de $1255^{30}$.

Protagonismo fundacional y enraizamiento en el lugar se combinaron con el que parece haber sido requisito indispensable: el vínculo señorial. Las fundadoras eran las titulares señoriales de los lugares donde fundaban porque así lo habían decidido los reyes, que podían haber creado dichos señoríos para ellas. Fue el caso de Alfonso X: en 1255 creaba uno para doña Mayor en tierras de Cifuentes, Alcocer, Viana y Palazuelos. No así Pedro I, que entregó a sus mujeres titularidades señoriales ya existentes, aunque sea destacable que se insertasen en genealogías femeninas: otorgó a María de Padilla el señorío de Astudillo, anteriormente detentado por su madre, la reina María de Portugal, y por otras reinas pasadas, así como por la propia Leonor de Guzmán, amante de Alfonso XI; y cedió a su hija mayor el de Tordesillas, que igualmente había sido de doña María y de su madre la reina. Incluía así a su amante y a su hija natural en la genealogía señorial de las reinas de Castilla y las hacía partícipes de beneficios propios de la familia real $^{31}$.

Esta triple dimensión vehicular, familiar, patrimonial y señorial, se concretó también en los monasterios, como si éstos hubiesen sido espacios de materialización de tales vínculos y un instrumento de visibilización de los mismos que, al tiempo, garantizaba su continuidad.

Así, las entidades monásticas fueron instrumentos de cohesión de la parentela de sangre de las fundadoras porque contribuían a aunar sus intereses y a crear o reforzar conciencia propia. Destacó la vía patrimonial. En Alcocer, muy poco después de que Mayor Guillén emitiese la carta de fundación, su hermano Pedro de Guzmán donaba una renta y justificaba su actuación por saber que he de dar algo en el monasterio... que fizo... mi hermana, estableciendo que las monjas estuviesen siempre obligadas a rogar por é $1^{32}$. Los otros dos casos se presentan sobre todo como engarces del componente femenino consanguíneo que contribuyeron a trabar genealogías femeninas. En Tordesillas, la infanta Isabel constituyó uno de los apoyos más importantes de su hermana, pero este gesto iba más allá en su capacidad de visibilizar la parentela femenina, pues la aldea que donaba había sido de

30 P. Martín, La fundación, p. 235; J.B. Sitges, Las mujeres, p. 383; A. Orejón, Historia, pp. 11-12 y 14 .

31 A. Vaca, Documentación, $\mathrm{n}^{\circ}$ 43, p. 54; P. Martín, Origen; AHN, Clero, 1689/10 y 13; ASCA, leg. 2/16, 11 y 3; leg. 2-II-8, caja 2; F. Simón, El monasterio, no. 15-16, 21 у 28, pp. 150-153 y 159-161; A. Orejón, Historia, apéndice 2, nº 8, pp. 195-196.

${ }^{32}$ AHN, Sellos, 55, no 4; Clero, 566/8, 10 y 12; P. Martín, Colección, nº 7, 13-14 y 17, pp. 170, 177 y 179-180; idem, La fundación, p. 237. 
su madre doña María. En Santa Clara de Astudillo documentamos la participación de las parientas de María de Padilla: su madre María González, su tía paterna Inés García o su propia hija Beatriz. La segunda legaba sus bienes al monasterio, pero solicitaba a su albacea, la madre de doña María, que dos años antes de entregarlos a las monjas socorriese con sus frutos a mujeres menesterosas del mío linaje, y hemos visto que también la tercera contribuía materialmente a la fundación; además, doña María otorgaba a su madre importantes responsabilidades de control sobre la comunidad monástica en caso de fallecer antes que ella.

Estas redes familiares femeninas se plasmaron institucionalmente, sobre todo en el hecho de que las primeras abadesas fuesen parientas de las fundadoras. Si algunas tradiciones señalan que en Alcocer lo fue una hija de doña Mayor y Alfonso X, Astudillo ofrece el ejemplo probado. La necesidad de observancia religiosa que se arguyó para obtener el control de la configuración comunitaria pudo ocultar en parte el afán de incluir a las parientas y a otras personas próximas. Resulta muy llamativo el énfasis sobre esta cuestión y la insistencia con que se solicitó tener bajo control dicha configuración. Durante toda la segunda mitad del siglo XIV hubo parientas de doña María de Padilla en el oficio abacial: la primera, su tía por parte de madre, Marina de Henestrosa; la segunda, probable sobrina, Guiomar Sánchez de Padilla ${ }^{33}$. Pero esto nos lleva más allá. La red de monasterios clarianos en la zona parecía estar colmada: al menos, había una comunidad en Reinoso de Cerrato y otra en Castrojeriz. Sin embargo, no hubo problema en fundar otro monasterio muy próximo, en buena medida, por el potente vínculo familiar. Santa Clara de Reinoso era un cenobio muy conectado con la familia materna de doña María: la abadesa doña Sancha Gutiérrez, documentada en $1339^{34}$, era su tía y de allí procedió su otra tía Juana, monja fundadora y primera abadesa de Astudillo. Con Santa Clara de Castrojeriz, donde doña María eligió monjas fundadoras ${ }^{35}$, no sabemos si había vínculo familiar, pero este gesto puede ser indicativo de otros lazos personales: cabría considerar que su segunda hija, Constanza, había nacido en 1354 en Castrojeriz. Y nos preguntamos si no hubo también afán político al servicio de la corona, ¿con un posible afán conciliador? No podemos determinarlo, pero este cenobio estaba vinculado a la familia de Garci Laso de la Vega, cabecilla del levantamiento nobiliario de Burgos contra el rey y asesinado

33 ASCA, leg. 2/3, 9, 10, 16, 22 y 23; caja 6; AHN, Clero, leg. 5312; F. Simón, El monasterio, $\mathrm{n}^{\circ} 16,20,26$, pp. 150-153 y 159-160; A. Orejón, Historia, ${ }^{\circ} 12$ y 19, pp. 154-155 y $170-172$.

${ }^{34}$ A. Vaca, Documentación, $\mathrm{n}^{\circ} 33$, p. 52.

${ }_{35}$ M. de Castro, La provincia, p. 235; F. Calderón, Primera parte, 310. 
por orden suya; además, doña María tuvo tratos con su viuda para completar la dotación de Astudillo ${ }^{36}$.

Por otra parte, las tres fundaciones compartieron su capacidad de "legitimar" las líneas de parentesco bastardas que sus fundadoras habían creado, de unir a sus integrantes en un interés común y de vincularlas a su familia de procedencia. Sobre todo María de Padilla trazaba una línea continua entre sus progenitores y sus descendientes y la enlazaba con la corona: quería que las clarisas de Astudillo rogasen por la vida e salud de mi señor el rey don Pedro e de mis fijas e por la mía e de mi madre e por el alma de mi padre e de los otros que son finados onde yo vengo. Además, implicaba a su descendencia y a la corona en el bienestar del monasterio. Ordenaba a sus hijas Beatriz y Constanza, a otros hijos o hijas que pudiera tener y a sus herederos, que guardasen la dotación para lograr la bendición de Dios y la suya; si fuesen contra ello, pedía a don Pedro y a sus sucesores que no lo consintiesen y que amparasen al monasterio para que Dios les diese parte en los bienes y oraciones de las monjas. Más lejos fue Tordesillas al tener entre sus objetivos principales otorgar visibilidad simbólica como línea dinástica legítima a una de las ramas de la nutrida descendencia bastarda de Pedro I.

También el monasterio se convirtió en instrumento al servicio de la dimensión señorial en su ejercicio y proyección. Es notoria la búsqueda y/o asunción consciente por parte de las fundadoras de la posición de poder que su protagonismo fundacional podía reportarles. Así, o se entrometían en la administración interna y regulaban aspectos importantes del funcionamiento comunitario, o pedían expresamente a las autoridades ser reconocidas patronas, lo cual significaba retener de forma vitalicia capacidades importantes de control interno y garantizar su libre ejercicio.

Estos afanes son muy visibles en Mayor Guillén, protagonista absoluta de la fundación de Alcocer y muy preocupada por controlar todos los aspectos materiales: otorgaba sus bienes, estipulaba cómo habían de distribuirse las rentas e imponía límites a su posible expansión patrimonial. Son notables en la infanta Beatriz, que diseñaba el modelo monástico de Tordesillas en su calidad de fundadora y señora del lugar. Pero se encarnaron muy especialmente en María de Padilla, que logró alcanzar una notable posición de poder en su creación clarisa, posición que buscó y ejerció con gran determinación. Fue así en lo económico y en el gobierno. Como doña Mayor, controló la dimensión

\footnotetext{
${ }^{36}$ El monarca había confirmado en 1351 los privilegios otorgados a Santa Clara de Castrojeriz por su padre, en parte obtenidos por mediación de Garci Laso I. L.V. Díaz Martín, Colección, vol. 1, $\mathrm{n}^{\circ}$ 180-181, pp. 228-230. Por su parte, tanto Garci Laso II como su esposa Leonor González de Cornado habían decidido enterrarse allí. En 1355 doña María compraba objetos litúrgicos para su monasterio a doña Leonor, viuda ya. ASCT, leg. IV, caja 12/1; F. Simón, El monasterio, $\mathrm{n}^{\circ}$ 58, pp. 177-178.
} 
administrativa material al organizar la dotación con una distribución detallada de las rentas que otorgaba según el número de personas y sus necesidades y se aseguró capacidad vitalicia de control; incluso, transfirió esta competencia a dos personas de su confianza - fray Juan de Balbás y su madre, doña María González-estableciendo que sólo tras su muerte pasase a la abadesa. Disponía además que, si a lo largo de su vida otorgase nuevos bienes, pudiera hacer con ellos lo que quisiere y disponerlos para su alma a su antojo o, incluso, otra persona a quien se lo mandase. Su empoderamiento también fue notorio en la administración interna, énfasis especial en el control del reclutamiento: no se podía crear dueñas ni poner o mudar abadesa sin su licencia y se reservaba la potestad de poner monjas. Además, obtenía del legado papal que el provincial franciscano estuviese obligado a designar dos visitadores y un confesor a requerimiento suyo. Finalmente, se preocupó por garantizar el ejercicio de estas competencias vitalicias: se reservaba para sí o para quien mandase tomar las rentas que había cedido en caso de que la comunidad no cumpliese lo que había establecido, y pedía al legado Guillermo que, además de confirmar todas sus disposiciones, la reconociese vera patrona ${ }^{37}$.

Estos monasterios fueron espacios de arraigo, vital y simbólico, y de enaltecimiento personales. Las fundadoras buscaron en ellos su lugar de habitación y memoria perpetuos. Doña Mayor residió en San Miguel del Monte y allí fue enterrada y es sabido que doña María, además de edificar un palacio junto al monasterio, residió por temporadas en la denominada "cámara de la reina" y dispuso su sepultura en el coro de la iglesia. Recordemos también aquí las tradiciones según las cuales la infanta Beatriz residió en Santa María de Tordesillas $^{38}$. La memoria perpetua asociada a la tumba -a veces incluso con signos de santidad en el cadáver, caso de doña Mayor-, a la autoría fundacional y al ejercicio del patronato, se plasmaba también en celebraciones litúrgicas. Todo ello venía a rehabilitar la vida irregular de estas mujeres. Éste habría sido su primer y fundamental objetivo: ya comentamos la función expiatoria de Alcocer y Astudillo. Pero, además, tanto este monasterio como el de Tordesillas se pusieron al servicio de la construcción de un personaje y de su memoria: María de Padilla reina. Si los miembros del complejo monástico de Astudillo se referían a ella como la reina doña María de Padilla en 1406, en la fundación de Tordesillas era expresamente mencionada de esa manera en todos los documentos y así se disponía que fuese rememorada en la liturgia.

Con estas fundaciones, pues, las fundadoras quedaban enaltecidas, adquirían un estatus de respetabilidad y se hacían perdonar su pasado irregular.

37 ASCA, leg. 1/4; F. Simón, El monasterio, nº 4, p. 141; A. Orejón, Historia, no 5 y 9 , pp. 142-146 y 151-152.

${ }^{38}$ Enrique Flórez llega a afirmar que fue enterrada allí. E. Flórez, Memorias, p. 641. 
Lograban altas cotas de empoderamiento y asumían posiciones de las que no habían gozado en su vida anterior; como vía de legitimación es posible considerar también el caso de la recién infanta Beatriz. Este enaltecimiento de su persona y de su sexo venía corroborado por las palabras de Pedro I al referirse a los beneficios que la fundación de Tordesillas reportaba a sus hijas: el estado y acrecentamiento de su honra y estado ${ }^{39}$.

Especialmente en el monasterio de Astudillo, el empoderamiento de la fundadora pudo favorecer el de la comunidad. Es muy significativo que el documento que declaraba vera patrona a doña María se expidiese al tiempo que otro, solicitado por ella, donde se fortalecía a las monjas y se afirmaba su autonomía respecto a la autoridad eclesiástica. Con los documentos del cardenal legado se garantizaba también la capacidad jurisdiccional del cenobio, su autonomía y su carácter privilegiado, además de preservarlo de violencias externas. Aspectos intensificados por las destacadas competencias señoriales de que gozó ${ }^{40}$. Pero sobre todo Santa María de Tordesillas se erigía como espacio de enaltecimiento simbólico femenino. Era así en el significado otorgado a la advocación, la fuerza del papel de la Virgen y la potencia de la oración de las mujeres, tanto de la Madre de Dios como de las monjas. Espacio de significación de la feminidad en su capacidad de mediación para los hombres y, en concreto, para los hombres políticos en guerra, fue también titular señorial.

Quedaría señalar una última cuestión que sólo afectó a Astudillo y Tordesillas. Ambos se planificaron con afanes de mejora de la vida religiosa en el difícil contexto de la crisis claustral del siglo XIV, marcada por procesos de relajación disciplinar y espiritual ${ }^{41}$. Hubo una progresión: doña María inició el planteamiento con el uso tan significativo de la expresión regularis observantia; su hija Beatriz lo recogió y lo amplió o, al menos, su padre quiso que fuese ella quien lo enunciase en el documento fundacional. Ambas mujeres subrayaban la clausura, el carácter de duennas ençerradas peculiar de las clarisas, así como la dedicación orante por encima del trabajo. No cabe considerarlas referencias casuales, pues en buena medida iban a contracorriente del contexto. Aquí radicaría otra posible razón del interés por controlar el reclutamiento y preservar la integridad de las comunidades. Y explicaría también la afirmación sostenida por los cronistas sobre la procedencia de Astudillo de las monjas fundadoras de Tordesillas. Doña María justificaba su dotación -de la que formaban parte los primeros derechos señoriales- con un argumento re-

39 ASCA, leg. 2-II-8, caja 2; F. Simón, El monasterio, p. 120; J.B. Sitges, Las mujeres, p. 387; Real monasterio, p. 97; ASCT, caja 44/1; J. Castro, Colección, n 94, pp. 83-86

40 ASCA, leg. 1/8; F. Simón, El monasterio, nº 5, pp. 141-142.

${ }^{41}$ J. García Oro, Los franciscanos, pp. 115-118. 
ligioso, la necesidad de que las monjas no se preocupasen por su subsistencia para poder más cumplidamente servir a Dios y estar en sus horas y oraciones sin necesidad de facer algunas obras que non podrían escusar de facer por aver cumplimiento de su mantenimiento. La infanta Beatriz iba más allá y manipulaba la distribución habitual de la jornada al establecer que las monjas estuviesen continuamente en oración y en el oficio divino desde la mañana hasta tercia, sin dedicar tiempo al trabajo. Y añadía otro aspecto disciplinar muy importante al erradicar de su fundación uno de los males más extendidos, la propiedad privada, un precepto que no formaba parte del diseño religioso de Astudillo ${ }^{42}$.

Coincidieron también en su autonomía respecto a las autoridades franciscanas, posición iniciada asimismo por doña María y que, además de las claves explicativas de autonomía y empoderamiento, ha de entenderse igualmente en esta dimensión de mejora religiosa. Cierto que Astudillo había sido asignado por el papa al provincial franciscano de Castilla, pero sus capacidades estaban mediatizadas por las amplias competencias reservadas a doña María y la comunidad. Tordesillas se diferenció en esto por su casi nula relación con las autoridades minoríticas. En cambio, en ambos destacó la presencia del franciscano fray Juan de Balbás, quizá confesor de doña María y, sin duda, persona de su confianza. No ha sido posible identificarlo, aunque su apellido revela un origen probable en la zona burgalesapalentina. Tampoco sabemos de qué convento procedía ni si había ejercido algún cargo, pero en 1359 era "morador" de San Francisco de Burgos: allí hacía trasladar la bula por la que Juan XXII eximía a las clarisas de pagar décimas y exacciones, prueba de su interés activo por la orden ${ }^{43}$. Su presencia no significó una renovación institucional vinculada a las autoridades franciscanas. Antes bien, se impuso el personalismo relacional, concretado en su asunción vitalicia de importantes competencias de gobierno interno en ambos monasterios. También hubo aquí progresión: si en Astudillo quedaba encargado por doña María de la supervisión administrativa, en Tordesillas la infanta Beatriz le otorgaba esta misma responsabilidad, pero establecía que no la ejerciese directamente y sí, en cambio, la labor de dirección espiritual -otro indicio de desapego material en este monasterio-, que no mencionaba la fundadora de Astudillo; tras su muerte, hacía recaer la búsqueda de sustitutos sobre los reyes de Castilla.

42 F. Calderón, Primera parte, p. 315. El ejemplo de conventualismo ofrecido por Santa Clara de Córdoba, en $\mathrm{M}^{\mathrm{a}} \mathrm{M}$. Graña, Autonomía.

${ }^{43}$ A. López, Confesores, p. 36; M. de Castro, La provincia, pp. 235-236. 


\section{LA PARTICIPACIÓN DE LOS REYES Y SUS POLÍTICAS}

Aunque tanto Alfonso X como Pedro I coincidieron en el respaldo que brindaron a unas fundaciones monásticas ligadas a ellos por vínculos personales, fueron muy diferentes sus formas de implicación.

El Rey Sabio fue protagonista de la voluntad fundacional de Alcocer, pero no tanto de su ejecución. En la formulación del objetivo y el impulso primero se unía su condición regia como ordenante a la personal: Mayor Guillén afirmaba que hacía monasterio con mandado e con plazer de mío señor don Alfonso. En cambio, en la puesta en marcha parece haberse involucrado de forma indirecta, sin tener protagonismo activo en las gestiones fundacionales y en la dotación patrimonial. Ésta procedía en última instancia de la corona en una medida importante, pero por mediación de la fundadora y su familia: por ejemplo, doña Mayor entregaba rentas que tenía en heredat de mío señor el rey don Alfonso y casi en los mismos términos se expresaba su hermano, el adelantado mayor de Castilla; el rey seguía interviniendo por esta vía cuando, años después, su hija Beatriz permutaba con las monjas el montazgo que les tollió mi padre por la renta que había recibido de él en Huete. El monarca se dedicó sobre todo a garantizar la estabilidad de la fundación: además de confirmarla de forma casi inmediata porque tenía voluntad de fazerle bien e mercet, ratificó las donaciones efectuadas por los parientes ${ }^{44}$. A lo largo del proceso ofreció muestras de una interacción con doña Mayor muy limitada, expresada en el lenguaje formal del protocolo regio.

Pedro I participó de forma mucho más directa, activa y continuada en las fundaciones de Astudillo y Tordesillas. También fue mayor su interacción personal con las fundadoras, totalmente implicado en sus vínculos amorosos personales, y mostró voluntad expresa por favorecer su autonomía y enaltecimiento. No debería olvidarse que, mientras el Rey Sabio había dado por finalizada su relación con Mayor Guillén al iniciar la fundación, don Pedro mantuvo e intensificó la suya con María de Padilla y se mostró especialmente cercano, con ella y con sus hijas. En el proceso creador de Astudillo procuró separar su acción de una voluntad fundacional que hizo recaer en doña María, así como el entero protagonismo del proceso. Por ejemplo, los canónigos de Palencia referían que el rey y doña María les habían escrito que era voluntad de ella hacer un monasterio; don Pedro se limitaba a mediar para que le otorgasen a ella licencia fundacional, lo que hacían viendo que era servicio de Dios y por cumplir la voluntad del monarca; algo similar sucedió en la petición de

\footnotetext{
${ }^{44}$ AHN, Clero, 566/5, 10 y 12; Sellos, 55, $\mathrm{n}^{\circ}$ 4; Archivo de la Real Chancillería de Valladolid, Pleitos Civiles, Quevedo (fenecidos), 2491-1, f. 18r; P. Martín, Colección, no 8-9, 14-15 y 17-18, pp. 170-173, 177-181.
} 
licencia al papa, al que ambos escribieron por separado como suplicantes pero dejando claro que la fundación era responsabilidad de doña María. ¿Fue así en la materialización fundacional? El rey, aun colaborando activamente, no dejó de reconocer el protagonismo de su amiga: en sus privilegios expresaba la grande voluntad que he de facer bien e merced e limosna a la comunidad del monasterio que doña María mandó facer o la gran voluntat que yo he delo agrandar e delo levar adelante. Como el Rey Sabio, mostraba su satisfacción: me plogo e me place ${ }^{45}$. En cualquier caso, la continuada serie de privilegios otorgada por don Pedro a este monasterio muestra su involucración directa y no encuentra parangón en las otras dos fundaciones.

La voluntad creadora de Santa María de Tordesillas sí fue de Pedro I. El obispo de Palencia, don Gutierre Gómez, recordaba que, cuando llevaron a Sevilla el cuerpo de la reina doña María, su mujer, nuestra señora que Dios perdone, el rey le dijo que era su voluntad dotar y edificar un monasterio en sus palacios de Tordesillas para duennas ençerradas de la... Orden de Santa Clara y bajo su advocación, y que le había pedido su licencia. Poco después, don Pedro disponía en su testamento una fundación a la que consideró mi monesterio. Así lo reconocía también el papa Urbano V en 1365 al confirmarla y señalar que el rey había edificado, fundado y dotado el monasterio con sus bienes propios. Era muy importante la elección del lugar, espacio familiar significativo: además de intervenir en su construcción con doña María, allí residieron y nacieron dos de sus hijos, uno de ellos don Alfonso, al que había declarado infante heredero y que acababa de fallecer ${ }^{46}$.

Sin embargo, el monarca quiso servirse de su hija mayor y heredera como responsable fundacional aunque fuese todavía una niña. El lenguaje empleado volvía a asumir forma de orden y resalta por su severidad: en su testamento de noviembre de 1362, don Pedro ordenaba a doña Beatriz hacer el monasterio como señora del lugar de Tordesillas y que consintiese en ello so pena de su maldición. En los documentos fundacionales suscritos meses después el rey figuraba como "fundador en relación” con sus dos hijas. Aquí moderaba el lenguaje y se limitaba a dar autoridad y licencia para el acto de fundación, a estar presente durante la redacción de los documentos y confirmar su contenido. Aunque las infantas se presentaban como responsables y protagonistas, señalaban que contaban con el espreso consentimiento $e$

45 ASCA, leg. $1 / 3$ y 1; caja 1; leg. 2/12, 16, 11 y 3; leg. 2-II-8, caja 2; F. Simón, El monasterio, $\mathrm{n}^{\circ} 1-2$ y 14-16, 21 y 28, pp. 138-139, 149-153 y 159-161; A. Orejón, Historia, $\mathrm{n}^{\circ} .4,12$ y 140, pp. 154-155; apéndice 2, nº 8, pp. 195-196.

46 J.B. Sitges, Las mujeres, 259; AGP, Registros, $\mathrm{n}^{\circ}$ 5587: Libro de bezerro..., 1713, vol. I, ff. 42 y 122-124; caja 4915/2; ASCT, caja 6/1 y 2; caja 1/2. No entramos aquí en la polémica sobre si la construcción del palacio fue iniciada o no por Alfonso XI a raíz de su victoria del Salado. J.C. Ruiz Souza, Santa Clara, pp. 22-25. 
mandado especial de su padre, que para todo daba su autoridad. Tampoco obviaron la dimensión relacional: doña Beatriz presentaba su iniciativa vinculada al rey en términos religiosos al indicar como razón principal de la fundación la gran devoción que ambos tenían a la Virgen y su deseo de que ella ganase favores para su familia.

La colaboración entre ambos monarcas y sus mujeres no siempre aparece suficientemente documentada, aunque sí quedó registrada en la memoria de sus contemporáneos. Las fuentes directas no equiparan a doña Mayor con Alfonso $\mathrm{X}$ en el proceso fundacional, pero su hija Beatriz, reina de Portugal, sí los situaba juntos en su memoria y en relación al monasterio de Alcocer refiriéndose a estas donaciones que mi padre, rey don Alfonso de Castiella et de León, et mi madre donna Mayor Guyllem... dieron et otorgaron a ese monesterio. Es grande el contraste con Pedro I y María de Padilla, que actuaban coordinados al dirigirse a las autoridades eclesiásticas ${ }^{47}$.

¿Qué interés podían tener los reyes en promover estos monasterios femeninos? ¿Por qué prefirieron que las fundaciones las protagonizasen las mujeres?

En los casos de Alcocer y Astudillo resulta evidente la necesidad de situar adecuadamente a sus amantes tras finalizar la relación, objetivo práctico muy distinto al fin expiatorio perseguido por las fundadoras. Ambos monarcas, cuando se casaron o tuvieron sus primeros hijos legítimos, hallaron en la fundación monástica el medio de alejarlas de la corte facilitándoles un lugar residencial propio, a lo que se sumaba la honra y prestigio que reportaba su condición de fundadoras. Pero estos objetivos, ¿no habrían podido satisfacerse con cualquier orden religiosa? ¿Por qué damianitas y clarisas? Dadas la fuerza y autonomía con que actuaron doña Mayor y doña María, no cabría dudar de que tuvieron capacidad de elegir la orientación regular. Pero tampoco cabría negársela a unos monarcas involucrados como ordenantes o participantes.

Se perfilan dos claves explicativas importantes. Una, que tanto la Orden de San Damián como la de Santa Clara eran las únicas órdenes religiosas exclusivamente de mujeres de aquel tiempo. El ensalzamiento femenino que estas fundaciones monásticas propiciaron se avenía muy bien con instituciones que eran referente simbólico de feminidad. Otra sería la política de ambos monarcas respecto a las órdenes mendicantes.

La fundación de Alcocer resulta atípica en el marco de la política fundacional mendicante de Alfonso X, monarca que desplegó un vasto plan de promoción de las nuevas órdenes religiosas en su reino ${ }^{48}$. Muestra cierta

47 AHN, Clero, 566/12; P. Martín, Colección, no 17, pp. 179-180; ASCA, leg. 1/3 y 1; F. Simón, El monasterio, n ${ }^{\circ} 1-2$ y 16, pp. 138-139 y 150-153.

48 Para situar su actuación en el marco del reinado, M. González, Alfonso X. 
precocidad cronológica, pues el Rey Sabio se dedicó a impulsar fundaciones sobre todo a partir de 1260 , y, especialmente, chocan la geografía de implantación y la orientación institucional. El carácter eremítico, el establecimiento en despoblado y el hecho de que Alcocer no fuese un centro urbano contrastan con la notoria inclinación de don Alfonso por impulsar fundaciones en ciudades. Contrasta también la ausencia de relación explícita con los franciscanos considerando su interés por vincular sus fundaciones femeninas a los frailes. Los intereses del monarca no encajaban del todo en la idiosincrasia de la Orden de San Damián. No se olvide que esta institución religiosa fue una creación de los papas y que con frecuencia trabó sus principales vínculos institucionales con Roma y los obispos. Cierto que las primeras seguidoras de Clara de Asís tuvieron que adoptarla por no haber otra posibilidad canónica durante largo tiempo. Pero también que los papas pudieron promover su difusión independiente. Cada monasterio requiere un análisis detenido para valorar su nivel de implicación en la espiritualidad y/o el movimiento minorítico o, incluso, su posible ausencia.

¿Cabría pensar entonces que la adscripción damianita fue resultado de una decisión independiente de doña Mayor? Probablemente era ésta la opción regular femenina que por entonces mejor podía adecuarse al espacio señorial en que se pretendía erigir el monasterio y a la peculiar situación de la fundadora. Encajaría con ello la tradición según la cual solicitó religiosas a la propia Santa Clara hacia 1252, es decir, cuando la comunidad de Asís estaba ya integrada en la Orden de San Damián, un elemento de prestigio añadido y que ligaba al monasterio con los carismas espirituales más punteros del momento. Quizá pudo interesar también el vínculo directo con Roma y la capacidad de actuación autónoma que posibilitaba.

Pero sospechamos que doña Mayor no decidió en solitario la adscripción institucional: la referencia de 1260 invita a considerar su sintonía con el rey. En el documento de dotación, la fundadora no mencionaba a la orden damianita, sino a las menoretas franciscanas, y personificaba en San Francisco su horizonte espiritual. Indicamos su posible inclinación por la regla inocenciana o la de Longchamp, pues ambas facultaban el vínculo con los franciscanos y la segunda, además, remitía a la familia real de Francia, con la que el Rey Sabio tenía lazos consanguíneos; el intento de implantación de esta última se ha sospechado en otros cenobios promovidos por el rey en fechas próximas a la culminación de Alcocer, como Santa Clara de Córdoba. A este respecto, aunque la documentación del monasterio no muestre relaciones con los franciscanos, es interesante señalar que el guardián del convento de San Francisco de Huete figuraba como testigo en la donación protagonizada por el hermano de doña Mayor un mes después de la dotación. Significativamente, este convento pertenecía a la custodia franciscana de Murcia, que se estaba 
creando justo por los años de 1260 y en la que, con el tiempo, se acabaría integrando el monasterio de Alcocer. Podría ser un dato indicativo de posibles contactos con los frailes en el origen de esta fundación aunque no existiese vínculo formal. ¿Hubo además un intento de "franciscanizarla" en sintonía con los intereses políticos de don Alfonso? ¿Explicaría esto las diferentes denominaciones aplicadas a la comunidad en 1259 y 1260 ?

No es posible responder, aunque resulta también llamativo que el papado se preocupase en 1262 por enfatizar la condición damianita del monasterio de Alcocer y su consiguiente observancia de la regla de San Benito y las constituciones hugolinianas. Por lo demás, la documentación del monasterio a lo largo del siglo XIII muestra que sus referentes eclesiásticos fueron el obispo de Cuenca y el papa. Habría que analizar a fondo la política mendicante del rey para poder valorar adecuadamente el lugar ocupado en la misma por esta fundación. En cualquier caso, no cabría dudar de su interés, como tampoco de otra destacada función política mostrada por este tipo de monasterios: su capacidad de cohesionar a la nobleza de servicio del rey y con él, en este caso, al destacado linaje de los Guzmanes; no se olvide, entre otras cosas, que el hermano de doña Mayor, don Pedro de Guzmán, era adelantado mayor de Castilla.

La conexión con Roma y los privilegios eclesiásticos fueron aspectos coincidentes con los monasterios de Astudillo y Tordesillas. Pertenecientes a la ya definida y reconocida Orden de Santa Clara, habían de vincularse a la Orden de San Francisco. Sin embargo, dicho vínculo se presenta llamativamente debilitado o incluso inexistente frente a la capacidad de control de las fundadoras, el rey y personas delegadas. En ambos monasterios resultaron determinantes el peso de las relaciones personales y clientelares y los intereses particulares de los fundadores. Ello fue posible, en buena parte, por la situación de crisis que atravesaba la orden franciscana en Castilla, carente de una propuesta de reforma bien perfilada a aquellas alturas del siglo XIV.

En aquel contexto difícil, los dos cenobios clarianos vinculados a Pedro I nacieron con afanes de mejora de la vida religiosa, aunque no como fruto de un plan amplio de reforma institucional promovido por él: al igual que antes doña María de Padilla, el rey no parece haber pretendido rebasar el horizonte de sus vínculos personales. Es posible que doña María decidiese la opción por las clarisas y el modelo de observancia. Invita a pensarlo su gran protagonismo creador y el peso de sus parientas monjas. Pero don Pedro, que sin duda asumió este proyecto, fue también autor al añadirle elementos nuevos en Tordesillas. El énfasis en la separación entre lo espiritual y lo material, plasmado en la obligación de pobreza individual y las disposiciones administrativas, era una novedad aportada por esta fundación y posible resultado de la experiencia anterior; quizá por ello el monarca no concedió el privilegio 
de libertad de herencia y donación documentado en Astudillo y sí aumentó las percepciones y derechos señoriales. Asimismo, en Tordesillas se consumó la independencia respecto a las autoridades franciscanas. Cierto que aquí no hubo entera coincidencia entre la infanta y su padre, lo que invita a preguntarse si hubo diferencias de criterio y, por tanto, un peso decisorio activo de la niña o un cambio de opinión del monarca. Frente a lo dispuesto por su hija, el rey desligaba a la corona de la responsabilidad administrativa y la hacía recaer en la abadesa y el visitador, término que, en principio, remitiría a la autoridad franciscana aunque no lo especifique; incluía la celebración de misas por varios capellanes que tanto podrían ser frailes como seculares; y encargaba la puesta en marcha de la fundación al obispo de Palencia, sin mencionar al provincial franciscano. No afirmaba expresamente una posible jurisdicción episcopal del cenobio y tampoco el papa Urbano en sus bulas, pero, ciertamente, en 1377 el papado eximió al monasterio de la autoridad del obispo.

La presencia de fray Juan de Balbás se explica en relación con el rey tanto como con doña María. Se ha sospechado que pudo ser también su confesor y, sin duda, era persona de confianza, pues figura como su testamentario. Quizá deba relacionarse con la presencia en el entorno regio de otro religioso, fray Fernando, éste sí confesor de don Pedro, testigo de la escritura dotacional de Astudillo y probable franciscano ${ }^{49}$. ¿Tuvieron algún peso estos frailes en las decisiones fundacionales y en la orientación por la Orden de Santa Clara? Tanto el objetivo de elevar el nivel de la vida religiosa como el extenso contenido teológico de los documentos más importantes pudieron obedecer a su actividad animadora. Sin embargo, su presencia no significó una renovación institucional vinculada a las autoridades de la provincia franciscana de Castilla. Antes bien, se impusieron el personalismo relacional y las competencias vitalicias.

Esta dimensión personal que parece haber sido tan característica de la actuación de Pedro I se hallaba presente en otros aspectos y muy trabada con cuestiones políticas, haciendo posible en el caso de Astudillo la conjunción armoniosa de sus intereses con los de doña María de Padilla. Vimos que la laxitud de los vínculos institucionales favorecía la autonomía de la fundadora y su empoderamiento y que la opción clarisa le permitía integrar a sus parientas monjas y conectar con dos cenobios clarianos muy próximos, Reinoso y Castrojeriz. Pero, desde la perspectiva del rey, ello significaba también la integración, siquiera simbólica, del que entonces era su privado, don Juan Fernández de Henestrosa, tío de doña María y hermano de la primera abadesa de Astudillo, Juana Fernández de Henestrosa. Desde esta perspectiva, Santa

\footnotetext{
${ }^{49}$ A. López, Confesores, p. 36.
} 
Clara de Astudillo habría sido la plasmación religiosa del ascenso político protagonizado por los parientes de doña María - miembros de la nobleza inferior- tras haber logrado sofocar el rey las rebeliones nobiliarias de inicios de su reinado. Entre ellas se sitúa la que en Burgos protagonizó Garci Laso de la Vega; su relación con Santa Clara de Castrojeriz podría quizá explicar en parte el vínculo de este cenobio con Astudillo, ¿en clave de recordatorio de la victoria del rey?

Sobre esto último no hay datos suficientes, pero resulta significativo que Astudillo y Tordesillas se fundasen coincidiendo con algunos de los giros políticos más importantes del reinado de Pedro I. La primera, precisamente tras sofocar las rebeliones, cuando el rey cambió de privado sustituyendo a Alburquerque por Henestrosa, primer paso de la política autoritaria que desarrolló desde 1353 respecto a la nobleza. La segunda, al poco de decidir legitimar su unión con doña María y nada más fallecer su infante heredero, mientras se encontraba en guerra con Aragón; no por casualidad, el objetivo de la victoria del rey se pensó como una de las dedicaciones principales de las monjas de Tordesillas. Al tiempo, ambos cenobios fueron espacios de cohesión y manifestación de los partidarios del rey o de sus familiares. Si Astudillo remite al gran privado Henestrosa y, por supuesto, a los Padilla, en Tordesillas participaron algunos de los pocos fieles que quedaban a don Pedro en la recta final de su reinado, especialmente el obispo de Palencia, don Gutierre, que siempre le había sido afecto y que, además, estaba muy bien relacionado con el papado. Los datos son escasos, pero revelan que la composición sociológica de ambas comunidades en estos primeros años no se nutrió de la nobleza media o alta, sino del grupo nobiliario inferior más cercano al rey. Esta dimensión clientelar se sospecha también en Tordesillas y enlaza asimismo con doña María: su mayordomo Juan González de Pedrosa ejercía este oficio en el monasterio en la década de 1370 y tenía dos hijas monjas, una aquí -futura abadesa- y otra en Astudillo ${ }^{50}$.

El vínculo especial de estos monasterios con el papado no sólo respaldó la autonomía de acción de los fundadores y su capacidad para controlar sus fundaciones. Significó también una vía de contacto con la Sede Apostólica en momentos de dificultad. Así en los inicios de Astudillo, coincidiendo con el disgusto pontificio por la irregular situación matrimonial de don Pedro, y, sobre todo, en la fundación de Tordesillas, cuyo carácter político se perfila de forma más evidente. No parece casual que la documentación pontificia se hiciese esperar dos años, hasta 1365, y que su expedición coincidiese con un paquete de bulas muy similar dirigido a Astudillo. Esta fundación ya estaba

50 L.V. Díaz, Los oficiales, 106; J. Zunzunegui, La legación, 145, nota 65; A. Arranz, Las elecciones, p. 445; S. Rodríguez, El monasterio, pp. 60-61. 
rematada, pero el rey volvía a solicitar la confirmación pontificia. Aunque se presentaba como sucesor de doña María en el patronato, tanto aquí como en Tordesillas figuraba como fundador y dotador inflamado con el celo de la piadosa devoción, además de suplicante de las concesiones. El papa situaba a ambos monasterios bajo la protección de la Sede Apostólica, mediatizaba la jurisdicción eclesiástica sobre los efectivos conventuales, confirmaba todos los privilegios otorgados por el rey y concedía los de la Orden de Santa Clara $^{51}$. Sin duda, el monarca deseaba garantizar protección a sus fundaciones en un momento político muy delicado, cuando veía amenazada su corona. Precisamente por ello, hay que hablar también de una cuestión de legitimidad. El monarca reivindicaba su protagonismo en el origen de ambos monasterios y solicitaba el apoyo directo del papado -que venía mostrando su apoyo a sus oponentes ${ }^{52}$ - en un gesto que lo presentaba como hijo fiel de la Iglesia, lo ennoblecía y autorizaba. Si el hecho mismo de fundar y/o favorecer a las instituciones religiosas ayudaba a la salvación del alma, don Pedro había mostrado ser muy sensible al valor religioso e histórico de este tipo de actuaciones ${ }^{53}$.

Como se ve, la Orden de Santa Clara brindaba en el concreto marco de la segunda mitad del siglo XIV posibilidades de actuación autónoma -en diseño religioso y gobierno- y de conexión personal y familiar que pueden explicar su elección. No obstante, ha de mencionarse también la inclinación espiritual del monarca. Cierto que su decisión de enterrarse con el hábito franciscano había sido compartida por antepasados como Sancho IV, más destacado por su política pro-dominica. Pero, aunque se trate de un gesto significativo, lo es mucho más que don Pedro declarase su devoción personal por Santa Clara: en 1357, afirmaba tener gran fiusa en Santa Clara y devoción a su monasterio de Astudillo ${ }^{54}$, causa de que lo favoreciese con privilegios. Confianza a relacionar con su devoción por la Virgen María -por lo demás, figura central en la espiritualidad clariana-, devoción que manifestaba en Tordesillas y en santuarios marianos del reino como Guadalupe ${ }^{55}$.

\section{UN SIMBÓLICO FEMENINO AL SERVICIO DE LA CORONA}

La Orden de Santa Clara constituyó un espacio y un referente simbólico femenino en su condición de orden religiosa sólo de mujeres y con la

${ }^{51}$ L. Waddingo, Annales, vol. VIII, núms. XXX-XXXIV, pp. 597-600; ASCA, leg. 1/14, 12,

13 y 15; AHN, Clero, 1689/17; F. Simón, El monasterio, nº 6-10, pp. 142-145.

52 L.V. Díaz, El pontificado, pp. 384-385.

53 ASCA, leg. 2/6.

54 Ibidem.

55 L.V. Díaz, Los oficiales, $n^{\circ}$ VIII, p. 119. 
primera fundadora carismática reconocida como tal en la historia de la vida religiosa, Clara de Asís. Teniendo esto en cuenta probablemente se entienda mejor su elección en situaciones que perseguían objetivos de legitimación y ennoblecimiento femeninos como las aquí revisadas. Fundar un monasterio de esta orden, incluso de una de sus antecedentes, la Orden de San Damián, no sólo legitimaba a mujeres de condición irregular -favoritas o bastardas- que acababan de ser promovidas a un estatus superior como titulares señoriales, infantas herederas e, incluso, reinas después de muertas. Respecto a otras órdenes religiosas, facultaba de forma especial tanto dicha legitimación como los intereses de enaltecimiento y empoderamiento que se perseguían. Esto fue así por el plus simbólico femenino que aportaba y por las idóneas condiciones canónicas que ofrecía en los momentos aquí estudiados: bien por tratarse del estadio damianita inicial, bien por fundarse en tiempos de crisis religiosa, lo cierto es que la peculiar red de inserción jurisdiccional en que se ubicaron estos monasterios favorecía la autonomía y capacidad de actuación de las fundadoras vinculándolas directamente al papado, fuente primera de legitimidad $\mathrm{y}$ prestigio en todo proyecto religioso.

Los titulares de la corona mostraron su interés por que así fuese colaborando en todas las fundaciones e, incluso, ordenando la ejecución de dos de ellas. Además de entender estos gestos como muestra de una preocupación por las mujeres que las promovieron y por su legitimación en el marco de la familia real entendida en sentido amplio, nos preguntamos cuál fue su calado dinástico. ¿Fueron estas comunidades favoritas de la corona?, ¿mantuvieron sus titulares una conexión especial con ellas a lo largo del tiempo?

La documentación es explícita en sus referencias al indudable interés personal de los monarcas impulsores: la expresión con placer que se les atribuyó o que utilizaron resulta muy indicativa. Sin embargo, en una dimensión institucional, aunque el mero hecho de que participasen en las fundaciones y entablasen algún tipo de conexión implicaba un vínculo con la corona, no mostraron interés por garantizar su perpetuación en el tiempo. En realidad, la conexión posterior de la monarquía con estos cenobios vino favorecida por intervención femenina, sobre todo por la acción de la reina Juana Manuel, esposa de Enrique $\mathrm{II}^{56}$. No deja de ser interesante que fuesen también mujeres -doña María de Padilla y la infanta Beatriz- quienes deseasen vincular sus fundaciones a la corona a perpetuidad.

En efecto, no fue ésta la postura de los reyes. Alfonso X se limitó a establecer un lazo entre la fundación de Alcocer y su persona al estipular que

${ }^{56}$ Para Alcocer y Tordesillas: P. Martín, Sobre la promoción y S. Rodríguez, El monasterio, pp. 273 y ss. 
el abadesa et todo el convento rueguen siempre a Dios por nos ${ }^{57}$, sin una referencia dinástica que incluyese a sus antepasados y descendientes. Tampoco a lo largo de su reinado mostró favoritismo por este cenobio. De nuevo Pedro I fue más allá en este ámbito al reconocerse formalmente patrono de los monasterios de Astudillo y Tordesillas y al enlazar lo personal y lo familiar con lo dinástico relacionando las oraciones por su salvación con sus antepasados, con su función como monarca y su memoria. Así lo manifestaba al pedir a las monjas de Astudillo que rogasen a Dios que le dejase vivir y reinar a su servicio y, tras su muerte, por su alma, que la lieve Dios al su reino, así como por las de su padre y madre y sus antepasados regios. Sin embargo, no parecía tener visión de posteridad y sólo mencionaba a los monarcas futuros al subrayar que la concesión de privilegios a la Iglesia garantizaba su memoria: era natural que todo obrador del bien quisiera que su gesto no se olvidase ni perdiese, sino que quedase recuerdo suyo en el mundo, algo que los reyes ponían por escrito en sus privilegios para que sus sucesores tuvieran que guardarlo y llevarlo adelante confirmándolo con los suyos ${ }^{58}$.

La ausencia de alusiones a la posteridad en el trono resulta doblemente llamativa en Santa María de Tordesillas, donde ni siquiera figuran las referencias habituales a la memoria de los antepasados. Sorprende en una fundación de tan indudable interés personal, familiar y dinástico. Don Pedro conectó su residencia, el señorío de la villa y su fundación monástica con su familia bastarda recién legitimada, pero no tan claramente con la dinastía donde la estaba integrando. Los engarces genealógicos se muestran en el hecho de otorgar el señorío anteriormente detentado por reinas de Castilla a su hija mayor y, sólo de admitir que el palacio hubiese sido iniciado por su padre Alfonso XI -sobre lo que no hay unanimidad-, también con los titulares de la corona, pues no disponía que las monjas tuviesen que rezar por sus antepasados y descendientes en el trono subrayando la genealogía regia; incluso, eliminó las disposiciones por las que su hija responsabilizaba a la corona de la administración del monasterio. Tampoco pretendió crear allí un panteón funerario, destino que reservaba para la capilla que estaba construyendo en la catedral de Sevilla, donde había decidido enterrarse con doña María y su malogrado hijo el infante Alfonso ${ }^{59}$. En realidad, en esta fundación llama la atención un cierto componente de inmediatez en dimensión familiar y política. El monasterio era de nuevo el instrumento de fusión de lo personal con lo político, esta vez referente a un problema concreto: el rey hacía gala de personalismo familiar en

${ }^{57}$ AHN, Sellos, 55/4; P. Martín, Colección, no 9, pp. 172-173.

${ }^{58}$ ASCA, leg. 2/6.

${ }^{59}$ J.B. Sitges, Las mujeres, pp. 259, 252; J.C. Ruiz Souza, Capillas reales, pp. 12-14. 
sus disposiciones, vinculaba a sus hijas bastardas a un lugar con el que todos tenían lazos afectivos y, al tiempo, creaba una comunidad orante femenina que pretendía de alto nivel religioso con el importante fin político de legitimar su unión con María de Padilla y los hijos bastardos que con ella había tenido, de ofrecerle cobertura simbólica como reina, de enaltecer a sus hijas, de rezar por todos ellos y de hacerlo también por su victoria sobre sus enemigos, es decir, de ayudarle a resolver sus problemas más graves.

Entendió que todos estos objetivos habían de concretarse en un monasterio de la Orden de Santa Clara. No deja de ser llamativo que, en su fundación de Tordesillas, don Pedro se equiparase de alguna manera a las mujeres en cuanto a los beneficios que buscaba obtener con ella: legitimidad, empoderamiento y apoyos. Entendió que tales beneficios, incluso la victoria y la salvación, eran posibles con la sola mediación femenina, celeste y terrena. Sin obviar el peso que pudo tener la previa fundación de Astudillo y el recuerdo de María de Padilla en su decisión, hemos visto también su inclinación personal. La autoridad que reconocía a la capacidad de mediación femenina manifestada expresamente en la "confianza" que afirmaba sentir por Santa Clara y por la Virgen, a quien tenía por abogada en todos sus hechos, y que indirectamente mostraba hacia la potencia de la palabra orante femenina en su comunicación con Dios.

\section{BIBLIOGRAFÍA CITADA}

Álvarez Borge, Ignacio, Órdenes mendicantes y estructuras feudales de poder en Castilla la Vieja (siglos XIII y XIV), "Revista de Historia Económica" 17/3 (1999), pp. 543-578.

Arranz Guzmán, Ana, Las elecciones episcopales durante el reinado de Pedro I de Castilla, "En la España medieval" 24 (2001), pp. 421-461.

Calderón, Fray Francisco, Primera parte de la Crónica de la Santa Provincia de la Purísima Concepción de Nuestra Señora de la Regular Observancia, transcripción y notas de fray Hipólito Barriguín Fernández, Valladolid, Diputación de Valladolid, 2008.

Castro y Castro, Manuel de, La provincia franciscana de Santiago. Ocho siglos de historia, Santiago de Compostela, Liceo Franciscano, 1984.

Castro Toledo, Jonás, Colección diplomática de Tordesillas (909-1474), Valladolid, Servicio de Publicaciones de la Diputación Provincial de Valladolid, 1981.

Díaz Martín, Luis Vicente, Los oficiales de Pedro I de Castilla, Valladolid, Universidad de Valladolid, 1975. 
Díaz Martín, Luis Vicente, El pontificado y Castilla en el marco de las relaciones internacionales de mediados del siglo XIV, "Archivos Leoneses" 35 (1981), pp. 351-386.

Díaz Martín, Luis Vicente, Colección documental de Pedro I de Castilla (1350-1369), Salamanca, Junta de Castilla y León, 1997, 4 vols.

Duchesne, Gaston, Histoire de l'abbaye royale de Longchamp, 1255 à 1789, París, H. Daragon, 1906.

Flórez, Enrique, Memorias de las reinas católicas, ed. facsímil, 2 vols., Valladolid, Junta de Castilla y León, 2002.

García Oro, José, Francisco de Asís en la España medieval, Santiago de Compostela, Consejo Superior de Investigaciones Científicas - Liceo Franciscano, 1988.

González Cristóbal, Margarita, Inventarios documentales. Monasterio de Santa Clara de Tordesillas, 1316-1936, Madrid, Patrimonio Nacional, 1987.

González Jiménez, Manuel, Alfonso X el Sabio: historia de un reinado, $1252-$ 1284, Palencia, Diputación, 1999.

Graña Cid, María del Mar, Las primeras clarisas andaluzas. Franciscanismo femenino y Reconquista en el siglo XIII, en Martí Mayor, José; Graña Cid, María del Mar (coords.), Las clarisas en España y Portugal, Actas del Congreso Internacional, Madrid, Editorial Cisneros, 1994, vol. 2, t. 2, pp. 661-704.

Graña Cid, María del Mar, Autonomía y poder de las monjas en el régimen de Conventualidad: ¿una ruptura evangélica? (Santa Clara de Córdoba, 1268-1495), "Miscellanea Francescana" 110 (2010), pp. 468-508.

Graña Cid, María del Mar, Reinas, infantas y damas de corte en el origen de las monjas mendicantes castellanas (c. 1222-1316). Matronazgo espiritual y movimiento religioso femenino, en Garí, Blanca (ed.), Redes femeninas de promoción espiritual en los Reinos Peninsulares (s. XIII-XVI), Roma, Viella - IRCVM, 2013, pp. 21-43.

Linehan, Peter, La Iglesia española y el Papado en el siglo XIII, Salamanca, Universidad Pontificia de Salamanca, 1975.

López, Atanasio, Confesores de la familia real de Castilla, "Archivo IberoAmericano" 31 (1929), pp. 5-75.

Martín Prieto, Pablo, Origen, evolución y destino del señorío creado para la descendencia de Alfonso X de Castilla y Mayor Guillén de Guzmán (1255-1312), "Temas Medievales" 11 (2002-2003), pp. 219-240.

Martín Prieto, Pablo, La fundación del monasterio de Santa Clara de Alcocer (1252-1260), "Hispania Sacra" 57 (2005), pp. 227-241.

Martín Prieto, Pablo, El monasterio de Santa Clara de Alcocer en la Edad Media, Guadalajara, Diputación Provincial, 2005. 
Martín Prieto, Pablo, Sobre la promoción regia de la orden franciscana en la Corona de Castilla durante el primer reinado Trastámara, "Hispania Sacra" LIX (2007) 51-83.

Martín Prieto, Pablo, Colección diplomática del monasterio de Santa Clara de Alcocer en la Edad Media. Parte I (1205-1325), "De Medio Aevo" 1 (2013), pp. 159-198.

Martín Prieto, Pablo, Formación y evolución del patrimonio del monasterio de Santa Clara de Alcocer en la Edad Media, "Hispania Sacra" 64 (2013), pp. 563-601.

Miura Andrades, José María, Frailes, monjas y conventos: las órdenes mendicantes y la sociedad sevillana bajomedieval, Sevilla, Diputación de Sevilla, 1998.

Orejón Calvo, Anacleto, Historia del convento de Santa Clara de Astudillo, Palencia, Imprenta de la Casa de Expósitos y Hospicio Provincial, 1917.

Ortega, Pablo Manuel, Crónica de la provincia franciscana de Cartagena, introducción Juan Meseguer Fernández; índices y coordinación general de la edición Víctor Sánchez Gil, Madrid, Editorial Cisneros, 1980.

Rodríguez Guillén, Santiago, El monasterio de Santa María la Real de Tordesillas (1363-1509), Universidad de Alcalá de Henares, 2010 (tesis doctoral).

Ruiz Souza, Juan Carlos, Santa Clara de Tordesillas, en Real monasterio de Santa Clara de Tordesillas, Madrid, Ministerio de Educación y Ciencia, 2005, pp. 19-27.

Ruiz Souza, Juan Carlos, Capillas reales funerarias catedralicias de Castilla y León: nuevas hipótesis interpretativas de las catedrales de Sevilla, Córdoba y Toledo, "Anuario del Departamento de Historia y Teoría del Arte (UAM)" 18 (2006), pp. 9-29.

Simón y Nieto, Francisco, El monasterio de Santa Clara de Astudillo. Índice de su archivo. Nuevas noticias de doña María de Padilla, "Boletín de la Real Academia de la Historia" 29 (1896), pp. 118-178.

Sitges, J. B., Las mujeres del rey don Pedro I de Castilla, Madrid, Est. Tipolitográfico "Sucesores de Rivadeneyra”, Impresores de la Real Casa, 1910.

Vaca Lorenzo, Ángel, Documentación medieval de la villa de Astudillo (Palencia), "Publicaciones de la Institución Tello Téllez de Meneses" 48 (1983), pp. 31-100.

Villalba Ruiz de Toledo, Francisco Javier, El monasterio de Santa Clara de Alcocer y su conexión con la monarquía (siglos XIII-XV), "Wad-alHayara" 16 (1989), pp. 319-324. 
Villalba Ruiz de Toledo, Francisco Javier, Propiedad y explotación del monasterio de Santa Clara de Alcocer en la Baja Edad Media, "Hispania Sacra" 46 (1994), pp. 405-412.

Waddingo, Luca, Annales minorum seu trium ordinum a S. Francisco institutorum, Romae, Typis Rochi Bernabò, 1731-1740.

Zunzunegui Aramburu, José, La legación del cardenal Guillermo de La Jugie a Castilla y Aragón (1355-1358), “Anthologica Annua” 12 (1964), pp. 129-156.

Fecha de recepción del artículo: noviembre 2013

Fecha de aceptación y versión final: febrero 2014 